\title{
Where the Eye Supplants the Ear
}

\section{How Sound Waves Are Made Visible and Analyzed with Complete Precision}

By M. A. Henry

THERE is in Cincinnati, Ohio, a beau1 tiful church edifice, which, when it was built a few years ago, was entirely lined with marble. It was soon discovered that the reverberation of sound within its walls made it almost useless as an auditorium. Since that time a sum almost equal to the original cost of the church has been spent in trying to improve the acoustics. But the defect still remains very noticeable and the church stands today a monument to our colossal ignorance of the science of acoustics. This building and thousands of others, in every city in the country, emphasize our need of a real knowledge of sound.

We are witnessing today the birth of such a science at Case School of Applied Science in Cleveland, where is the best equipped laboratory in the world for photographing and analyzing sound. Dr. Dayton C. Miller, who is in charge of the laboratory, is devoting his life to the new science and today is one of the best authorities on the physical nature of sounds.

Dr. Miller has developed the general science of sound, especially with its relation to musical instruments. Until the death two years ago of Prof. Wallace C. Sabine of Harvard University, the two men worked in conjunction, Prof. Sabine devoting his energies to a study of the acoustics of buildings. Before his death he was able to predict accurately the acoustical properties of a room or building from a study of the blue prints and to correct any defects before actual construction was begun.

The work begun by Prof. Sabine is being carried forward now by Dr. Paul E. Sabine, lately an assistant to Dr. Miller, at a specially constructed laboratory at Geneva, Ill. This laboratory was endowed by Col. George Fayban for Prof. Wallace Sabine but was not completed until after his death. Meanwhile Dr. Miller is fitting assistants to carry on this work after him and there are five advanced students now at work at Case School. There has also been recently established at Case the Wallace Clement Sabine Research Fellowship in Acoustics, which has for its purpose amplification of the work begun by Prof. Sabine.

Before it is possible to analyze sound waves, some

$T$ is rather remarkable, when we come to think of it, that the phonograph, which is essentially a machine for producing sound, should have been brought to such a high state of development while our knowledge of the fundamental principles of sound and our means for acquiring such knowledge were both in a very low state. But if the makers of the early phonographs knew little and cared hardly more for the theoretic bases of their instruments, today in the race for better performance much attention is paid to these mattcrs. Scientific sound analysis depends almost wholly upon the work done by Professor D. C. Miller of Case School-the up-to-date methods of investigating the properties of sound waves by photographing them were almost altogether brought into being by him and his associates. The story of these methods might almost qualify for a place in the Romance of Inoention.-THE EDITOR. wave form as shown at the left For a more superficial study of sound waves, a drum having around its out side diameter a series of flat mirrors, is substituted for the photographic film and the dot of light from the small spindle mirror is refiected to a darkened screen. As the drum is revolved the dot of light moves from the top to the bot tom of the screen. Each succeeding mirror on the drum sends a dot of light across the screen and when the speed of the drum is sufficient, the dots follow each other in such rapid succession that they appear as a solid line of light. This arrangement imparts a longitudinal di mension to the sound waves, just as the rotation of the photographic film did, but it is now possible to see the wave form with the eye, at the very instant the sound is being produced.

The sound waves photographed by this machine are, The sound waves photographed by this machine are,
of course, nearly always of a complex nature, consistng of the combination of a number of simple back-and-forth wave movement. Dr. Miller has improved a machine, called the "harmonic analyzer" for mechanically analyzing this complex wave into its simple wave components. And he has not only succeeded in photographing soun! waves and analyzing them but can reconstruct, from the sound wave, the original sound itself.

Supposing, for instance, that we wish in reconstruct such a simple sound as the vowel $a$, as in father. We stand before the phonodeik and utter the sound. A photograph of the wave form is secured and this, by means of the harmonic analyzer, is reduced to its simple components. Then organ pipes, each of which produces a simple sound wave motion, al ready determined, are matched to the
A tiny mirror is attached to the spindle and a pinpoint of light from an arc-lamp is allowed to fall on the mirror. The point of light is refiected to a revolving drum, which holds the photographic film. The vibration of the diaphragm caused by sound waves produces on the film the traverse form of the wave an the rotation of the film at a set speed gives the wave its longitudinal form. A tuning fork arrangement throws dashes of light on the film and these indicate the duration in hundredths of seconds of the reen simple sound waves which make up the vowel $a$, as you uttered it. These pipes are all connected to a source of compressed air and are sounded simultaneously. The vowel $a$, with the very inotations of the speaker's voice, is heard. So exact a reproduction can be made that it is often impossible for a person in an adjoining room to tell whether he is hearing the person's voice or the mechanical reproduction.

If the pipes are sounded before the phonodeik, the record secured corresponds almost exactly with the original voice photograph. Of course, not all voices make the same record for the verwel $a$, as in father. It has been found by experiment that it usually takes about twelve pipes to reproduce the sound as spoken by a baritone voice, about six pipes for a woman's voice, eight for boy's voice, and three for a baby's voice.

By placing a collapsible rubber tube between the air supply and the pipes and

(Continued on page 468)

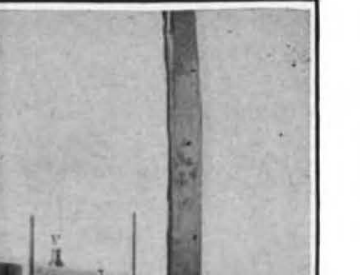
that they reflect no sound. Distortion of
the sound to be photographed by other waves is thus avoided. The instrument
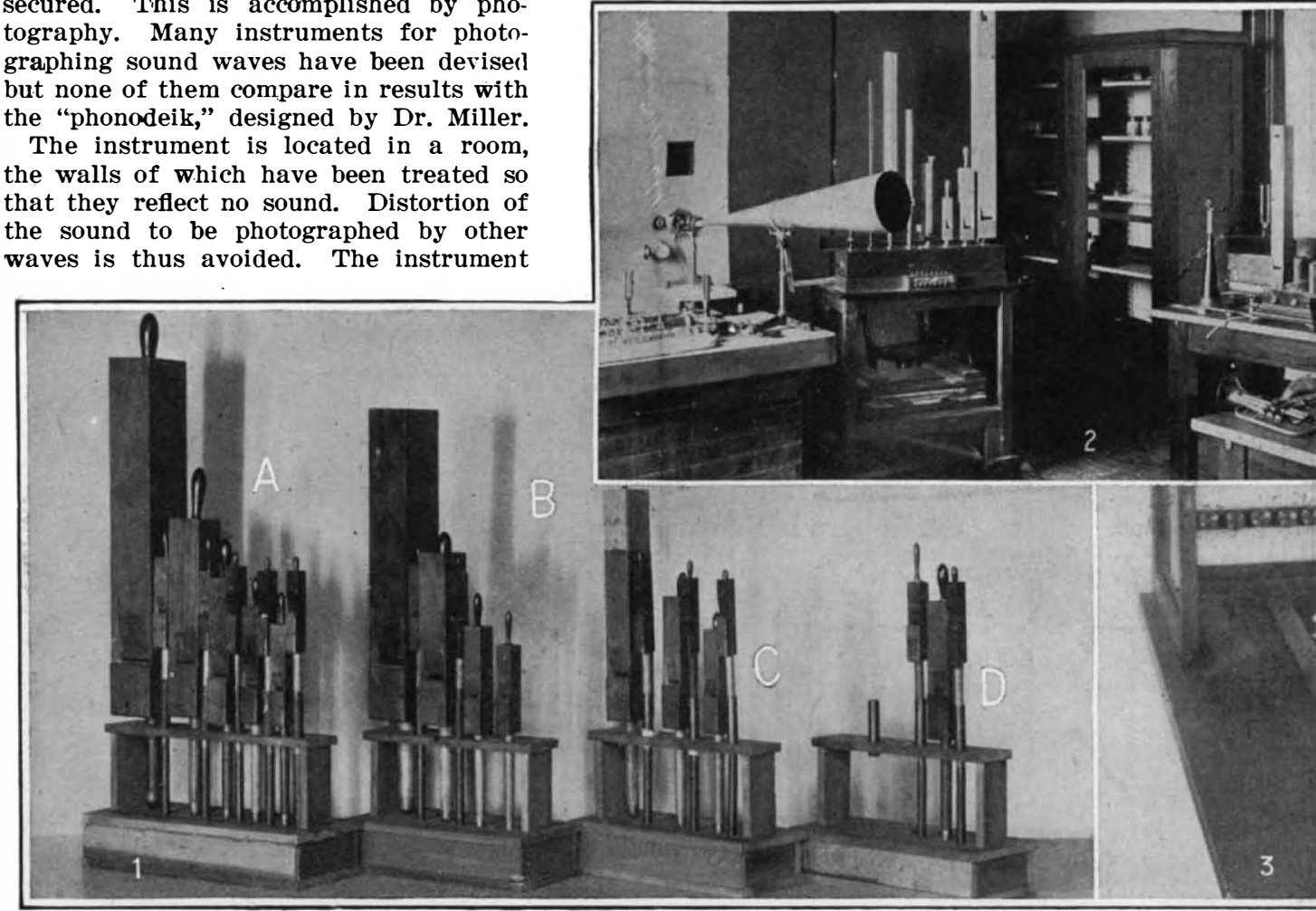

1.-Organ pipes set up to reproduce the vowel $a$ of father in $(A)$ a man's baritone, $(B)$ a boy's voice, $(C)$ a woman's voice, $(D)$ a baby's treble. 2.-The laboratory for sound analysis in the Case School. 3.-The harmonic analyzer that splits the sound waves up into their component parts.

The apparatus employed in the photographic analysis of sound waves 


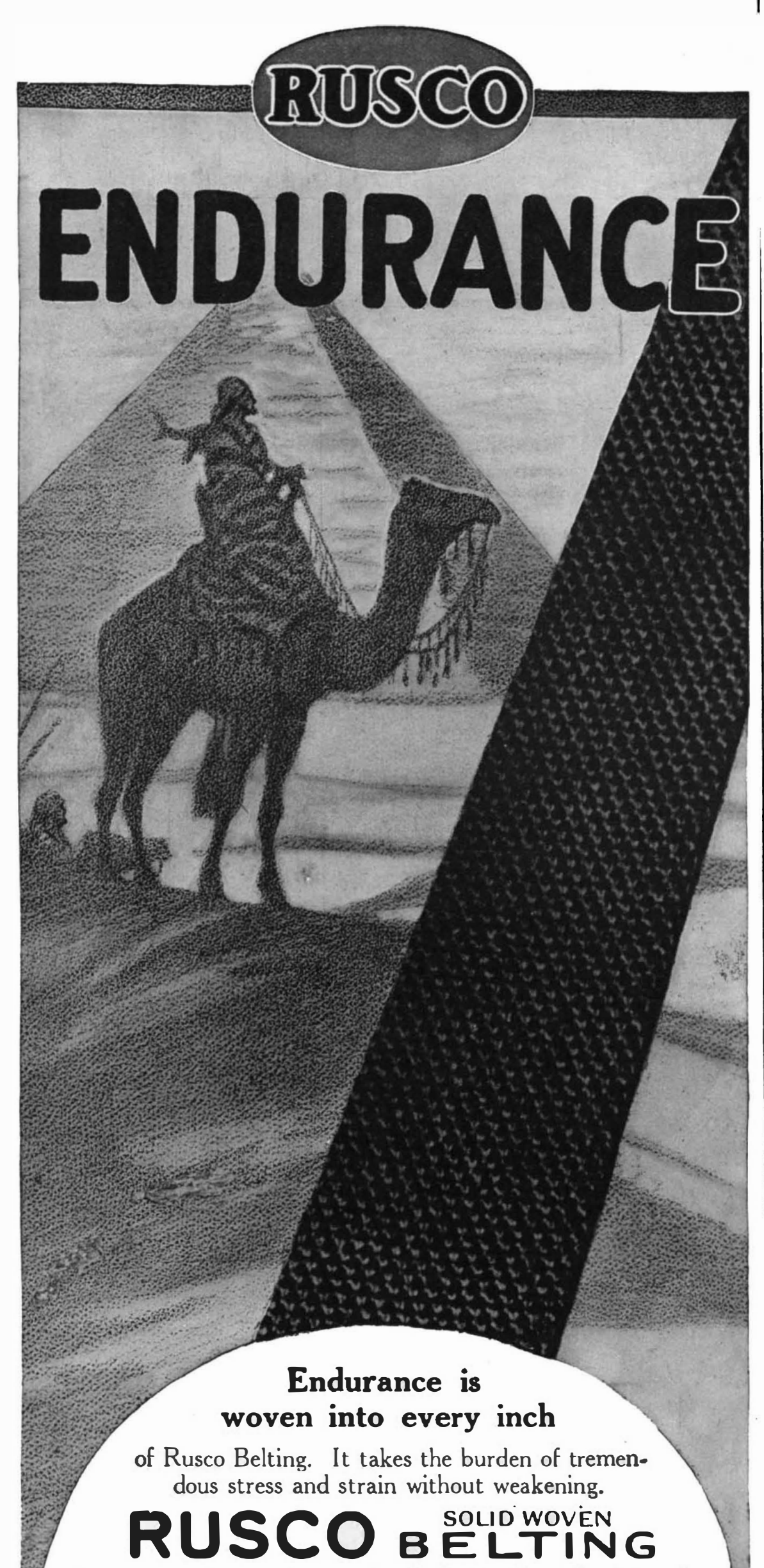

has great resistance to wear, has little stretch, and grips positively. Neither water, oil nor steam can impair Rusco efficiency.

\section{THE RUSSELL MANUFACTURING CO. 38 Factory Buildings 25,000
Established 1830}

501 Russell Avenue

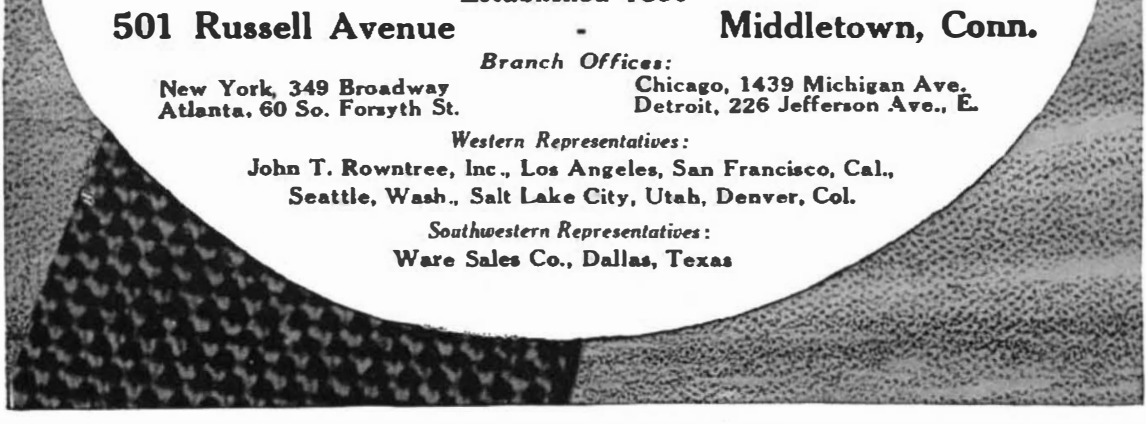

The Torpedo Motor Boat (Continued from page 466)

were made on the British fleet at Jutland, it will be possible, for the same cost, to launch several hundred of these little craft against the enemy. The endeavor, of course, would be to separate them into groups of from 50 to 100 and bring them to bear upon the enemy from various points of attack. For this purpose they would be drilled to act in regular formation, and no seagoing officer will deny that a highly developed, thoroughly trained and very numerous fleet of these craft would be a most puzzling problem for the commander-in-chief of the fleet that was attacked, or that it would afford magnificent opportunities for skillful and daring tactics and seamanship on the part of the torpedo boat flotilla commanders.

In drafting out the designs of this handsome and seaworthy craft, the architect has had in mind its use in times of peace as a captain's barge; a service for which, on account of its speed, seaworthiness and roomy accommodation, it would be admirably fitted. Emptied of torpedoes and with an awning and shelter canvas built above and around the cockpit and suitably cushioned, these boats would perform most excellent service of this kind and would undoubtedly be popular throughout the fleet. They are small enough and light enough to be hoisted up and housed on board a battleship, yet they can be stripped and loaded with torpedoes ready for action at very short notice.

\section{Exploiting the Inventor-III} (Continued from page 452)

as such, and strictly on its merits. But the promoters did not choose to do business on this basis. Stock is cheaper to manufacture than carburetors, and brings more; so they used the instrument merely as a basis for stock issue. In this connection, of course, they made claims for the carburetor which were quite impossible of substantiation. Yet they apparently substantiated them by actual performance. The answer was very simplewhen once it was known.

An automobile to the average citizen represents a fairly complicated piece of apparatus. But its engine is accessibleits works can be seen. And if a man look under the hood and see one pipe going to the carburetor, and if he look under the seat-supposing that it is that kind of a car- and see one pipe coming from the gas pipe, the chances are quite infinitesimal that he is going to lie on the ground and roll himself under the car to verify that these pipes are one and the same pipe. So the man selling this Wonderwiz carburetor put a concealed auxiliary gas tank under the front seat, and connected it also with the gasoline line. The car was used first with an ordinary carburetor, with the intake from the auxiliary line closed, and in this condition was run some measured miles-of course on measured gasoline from the rear tank. Then the Wonderwiz carburetor was installed and the same miles run, but the measured gas in the rear tank showed only half as much use. The reason was simple enough -in the interval between the two test the stop-cock connecting the auxiliary tank with the carburetor was opened and the carburetor was drawing gas from two tanks. Thousands of dollars were taken from the public in stock subscriptions on the strength of these tests-but the Wonderwiz never made its appearance on the market. If a man-prospective or actual investor or anybody else in the worldasked to buy one and have it installed on his car, he was told that "no one can buy these carburetors until we have our factory in operation, so that we can supply all the demand that will result from its use ; and then stockholders will be given
The Story of Radium (Continued from page 454) The amount of radium required has been determined by a long series of experiments. The more radium used, the brighter the glow, but the quicker the deterioration. But, it has been found, the luminosity is not in exact proportion to the amount of radium used and a quantity has been determined which gives the greatest luminosity and the longest life for the least money.

The commercial material now available is guaranteed for the life of the instrument on which it is used. It is supplied to the manufacturer as a yellow powder. It is mixed with an adhesive and applied to the work at hand with the tip of a camel's hair brush. Care is taken not to brush the material but to place it on the surface drop by drop, so as not to crush the zinc crystals. It is interesting to note that the deterioration of the substance is not due to failure of the radium, but to a breakdown of the zinc crystals, due to the bombardment of radium particles. No known substance will stand up under this bombardment. New uses are constantly being discovered for this material. A company is now in formation for the manufacture of luminous house numbers in large quantities. The best known use is in the luminizing of clock and watch dials and as locaters for electric switches. Some of the later applications are its use as keyhole locaters, on airplane and automobile instruments, ships' compasses and telegraph dials, mine signs, steam gages, pistol sights, poison bottle indicators, bedroom slipper buttons, furniture locater buttons, theater seat numbers, automobile steering-wheel locks, etc. Two recent novel pplications are in the manufacture of luminous fish bait and glowing eyes for toy dolls and animals.

\section{Where the Eye Supplants the Ear} (Continued from page 456)

pressing on it, to retard the air flow and then increase it successively, the pipes can be made to say Ma-ma in a very realistic manner. By quickly interrupting the air passage, the pipes can be made to say Pa-pa. It is a point of rather curiou interest that Dr. Miller believes the words mamma and papa originated from a baby's unconscious interruption of its cooing, in just such a manner. The baby. utters the sound $a$, as in father, becatuse this is perhaps the simplest of all spoken sounds.

It is quite possible that more complicated sounds, even complete words, could be reproduced mechanically, but the practical value is not readily apparent Aside from the acoustics of buildings, and the improvement of musical instruments, however, there are many applications of the new science, such as the elimination of noises in machinery and elsewhere, the study of language, improvement of public speaking, singing, etc. At present however, the development of the basic science is receiving first thought.

\section{The Geology of Ripple Marks} (Continued from page 457)

to water which flows in a single direction; and that the symmetrical marks occur when the water flows now in this direction and now in the opposite direction. It seems that the long gentle slopes are always on the side from which the current flows and the steep slopes on the side towards which it moves. Sand grains are, it is understood, carried along up the gentle slope and dropped over or onto the more precipitous side. That is, the flowing current erodes the long slopes ano builds up the short ones. A progressive movement of the group of current ripple marks is thus brought about. They slowly migrate in the direction of the water movement

Another curious fact, first noted, apparently, by Prof. G.-H. Darwin, is the (Continued on page 470) 